Images du travail, travail des images

$9 \mid 2020$

L'apprentissage et l'enseignement professionnel en images

\title{
Les filles du technique : apprenties dactylographes
}

Marianne Thivend

\section{OpenEdition}

Journals

Édition électronique

URL : http://journals.openedition.org/itti/538

DOI : 10.4000/itti.538

\section{Éditeur}

Université de Poitiers

\section{Référence électronique}

Marianne Thivend, «Les filles du technique : apprenties dactylographes », Images du travail, travail des images [En ligne], 9 | 2020, mis en ligne le 01 septembre 2020, consulté le 14 avril 2021. URL : http:// journals.openedition.org/itti/538; DOI : https://doi.org/10.4000/itti.538

Ce document a été généré automatiquement le 14 avril 2021.

Images du travail, travail des images 


\title{
Les filles du technique : apprenties dactylographes
}

\author{
Marianne Thivend
}

Photographie : Centre d'apprentissage pour jeunes filles. Le cours de sténodactylographie, la classe en activité.

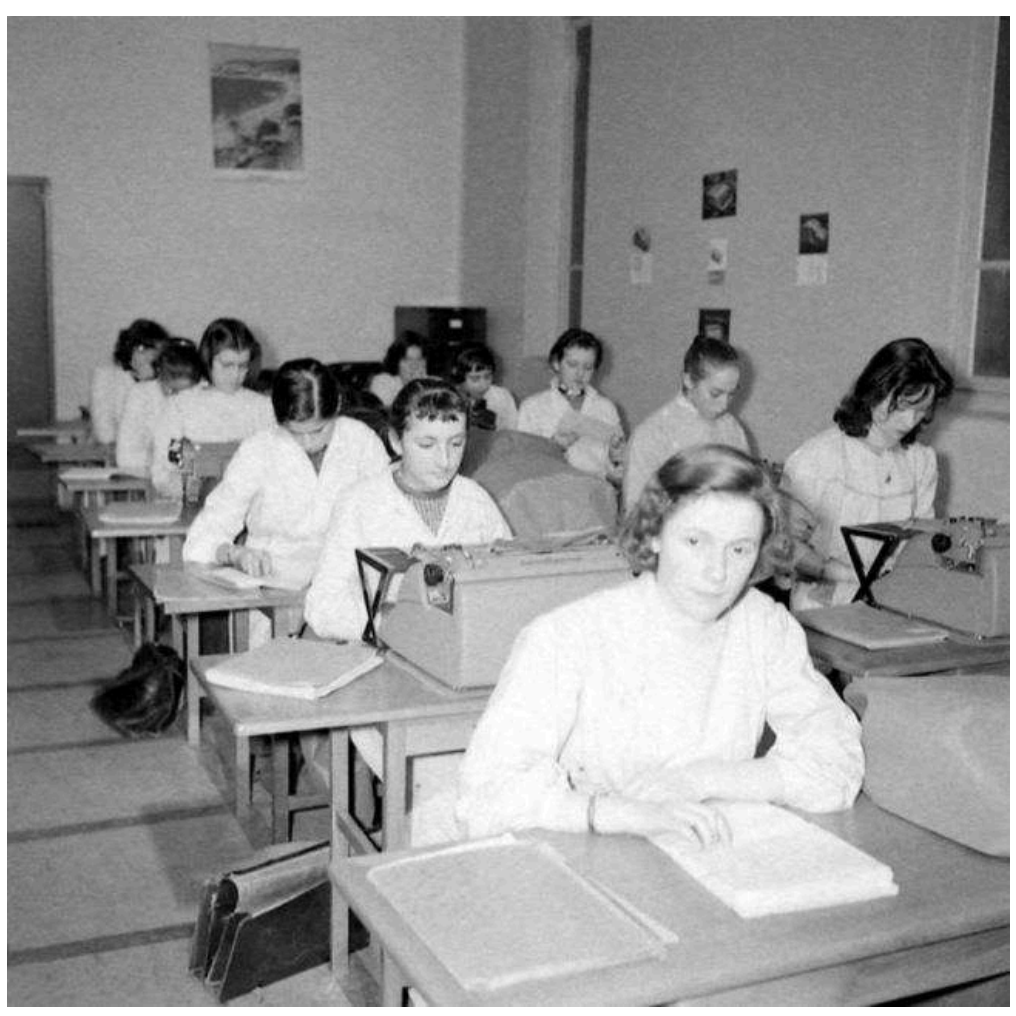

(C)Pierre Allard, I.P.N., 1958

Le cliché est signé Pierre Allard, sans doute issu d'une commande de l'Institut Pédagogique National. Le photographe entreprend un tour de France de l'école, de la maternelle au lycée, des cours de philo aux centres d'éducation surveillée, ce qui 
l'amène en 1958 à Bourgoin-Jallieu, commune industrielle du Nord de l'Isère. Un an avant sa transformation en collège d'enseignement technique avec la réforme Berthoin, le centre d'apprentissage recrute essentiellement à partir des classes de fin d'études ou des cours complémentaires, des jeunes admises après un concours d'entrée très sélectif. Emblème de la formation ouvrière, de celle de l'ouvrier qualifié des industries mécaniques et électriques, le centre d'apprentissage est également un lieu de scolarisation majeur pour les filles. Dans les années 1950, elles forment $35 \%$ de l'ensemble des effectifs (Pelpel \& Troger, 1993). Le certificat d'aptitude professionnelle (CAP), préparé en trois ans dans ces établissements, est donc aussi un diplôme féminin puisque lors de cette période, la part des filles chez les reçues ne descend jamais en dessous de $40 \%$ (Moreau, 2013).

2 L'heure n'est cependant pas à la mixité des lieux de formation, la photo en témoigne, et en 1958 , seulement $13,8 \%$ des centres d'apprentissage sont mixtes et $30 \%$ n'accueillent que des filles (Idem, p. 217). Acceptées au compte-goutte dans les spécialités de l'électricité ou de la mécanique de précision, elles sont très majoritairement orientées au sein des deux filières construites pour elles dès le début du siècle, celles qui mènent aux métiers de femmes (Perrot, 1987) désignés comme tels pour les qualités alors perçues comme innées, physiques et morales, qu'ils mettent en œuvre: ceux de la couture et de la confection (couture, lingerie, mode, vêtement), ceux du bureau et du commerce. La classe photographiée prépare sans doute au CAP de sténodactylographie, le plus féminisé des CAP commerciaux : $95 \%$ des reçues à ce CAP sont des filles en 1963 quand le CAP d'aide-comptabilité est plus mixte avec $44 \%$ de filles parmi les reçues (Thivend, 2013). À la fin des années 1950, face à un secteur de la confection en déclin, les formations commerciales sont plébiscitées et scolarisent désormais plus de la moitié des effectifs féminins de la filière professionnelle.

3 La photo frappe par sa lumière, que dégagent les blouses blanches, immaculées, portées par les jeunes filles, blancheur qui contraste avec le gris sombre habituel des blouses des jeunes apprentis des filières industrielles. Le message est clair: les métiers de bureau sont faits pour les femmes car ils offrent un environnement propre et sain. En 1953, la revue d'orientation Avenirs éditée par le Bureau Universitaire de la Statistique ne manque pas de conseiller la filière aux jeunes filles car elle convient à « leurs goûts et leurs aptitudes et leur permettent de faire valoir leur qualité d'ordre, de précision, de finesse, de dévouement " (Avenirs, 1953). Ces «qualités ", qui relèveraient d'une nature féminine, masquent ainsi les savoir-faire et savoir-être appris au quotidien dans les classes, et plus tard les qualifications. L'ordre figure au premier chef : des tables où rien ne traîne, papiers systématiquement à droite de la machine, machines en marche ou au repos recouvertes de leur protection. Et les compétences techniques sont bien là. C'est aux jeunes filles, très concentrées, de faire rendre à la machine toute sa productivité au terme d'un long apprentissage qui repose sur quelques techniques: taper sans regarder le clavier grâce au porte fiche qui cache le jeu des doigts, se tenir droite... Mais l'essentiel, la rapidité d'exécution des tâches d'écriture, n'est pas représentable sur une photo. Ce sont les épreuves pratiques du CAP de sténodactylographe qui viennent fixer ces normes de vitesse (Arrêtés des 11 octobre 1949 et 14 mars 1950). Elles comprennent une dictée sténographique d'un texte de 300 mots pendant trois minutes avec une heure accordée pour la traduction orthographiée et présentée parfaitement, une copie dactylographiée à la vitesse de 25 mots à la 
minute durant 15 minutes, une prise de deux lettres en sténo et présentation dactylo avec préparation des enveloppes en 20 minutes.

De cette photo, émane finalement une atmosphère douce et tranquille qui contraste avec certains des espaces de travail qui attendent ces futures employées à leur sortie, emplis du bruit des machines à écrire et rythmées par les cadences effrénées de la production des papiers.

\section{BIBLIOGRAPHIE}

Avenirs, « Les carrières féminines », (1953), n53-54.

Moreau G. (2013), « Le CAP, quel genre de diplôme ? », in Brucy G., Maillard F. et Moreau G. (dir.), 2013, Le CAP. Un diplôme du peuple 1911-2011, Rennes, PUR, p. 213-231.

Pelpel P. et Troger V. (1993), Histoire de l'enseignement technique, Hachette Education, p. 194.

Perrot M. (1987), « Qu'est-ce qu'un métier de femmes ? , Le Mouvement social, 140, VII-IX, p. 3-8.

Thivend M. (2013), « Le genre des CAP commerciaux », in Brucy G., Maillard F. et Moreau G. (dir.), Le CAP, op. cit., p. 149-162. 